[The Version of Record of this manuscript has been published and is available in Textual Practice, vol. 35, no. 9 (2021), https://doi.org/10.1080/0950236X.2021.1964735]

\title{
Imagining Marshall McLuhan as a Digital Reader: an Experiment in Applied Joyce
}

\author{
Alan Galey \\ Faculty of Information and Department of English \\ University of Toronto
}

Was McLuhan's greatest, most comprehensive work not his published writing but his reading? John Durham Peters makes this provocative suggestion in his reassessment of McLuhan's legacy on the evidence of McLuhan's own library, now held at the University of Toronto's Thomas Fisher Rare Book Library. ${ }^{1}$ McLuhan's own published books, with their fragmentary, aphoristic, and maddeningly under-referenced claims about writing, printing, and readers, can make vexing reading for book historians in the present. But Peters suggests a different way for nonMcLuhanites to approach this important but difficult body of work: 'what we have of McLuhan via his writings is bits and pieces and fragments. The great McLuhan Gesamtkunstwerk, the total work of art, is actually his library'. ${ }^{2}$ Whatever we make of McLuhan the published author and pop culture icon, his library can show us many McLuhans, to echo the title of the Fisher Library's 2018 symposium on the occasion of its addition to UNESCO's Memory of the World register. ${ }^{3}$ My interest is in McLuhan the annotating reader, and specifically as a reader of his favorite literary author, James Joyce. Having explored the material evidence of McLuhan's reading of Ulysses in a previous article, my purpose here is to use McLuhan's reading as a mirror

\footnotetext{
I am grateful to Paula McDowell for the invitation to present this work at the Reading McLuhan Reading symposium at New York University in 2020, and to the audience and the other presenters for their questions and comments. For various forms of help with the research, I also wish to thank Nicole D'Angela, Michael Groden, Stephen Hockema, H.J. Jackson, and Ellen Forget - though any errors are my own. Special thanks to Michael McLuhan and the McLuhan estate for permission to use images of manuscript material, to the Thomas Fisher Rare Book Library, and to the Social Sciences and Humanities Research Council of Canada for supporting this work through an Insight Grant. This article is dedicated to the memory of Michael Groden, a great teacher who inspired his students to make Joyce's works a lifelong exploration.

${ }^{1}$ John Durham Peters, 'Reading Over McLuhan's Shoulder', in Sarah Sharma (ed.), Many McLuhans or None At All, spec. issue of Canadian Journal of Communication, 44.4 (2019), p. 496. The Fisher Library offers detailed finding aids for McLuhan's books and the various manuscript and ephemeral materials found within them. (See the Fisher's website at https://fisher.library.utoronto.ca/, and look under Manuscripts Holdings / A-Z Index - Manuscript Finding Aids / McLuhan, Marshall.) These finding aids were developed by Andrew McLuhan and Fisher librarian Jason Nisenson, and include a guide to the abbreviations and multiple hands - those of Marshall and Eric McLuhan - that appear in many of the books. See also Andrew McLuhan's contribution to this special issue and his blog, Inscriptorium: https://inscriptorium.wordpress.com.

${ }^{2}$ Peters, 'Reading Over McLuhan's Shoulder', p. 496.

${ }^{3}$ Papers from the symposium appear in Sharma (ed.), Many McLuhans or None at All, cited in note 1.
} 
for digital practices in our present and recent past. ${ }^{4}$ McLuhan is often invoked as a prophet of the digital era generally, but this article focuses on a different and more specific question: would it be possible to imagine McLuhan's reading as his Gesamtkunstwerk-would the circumstances for such a claim even be possible-if McLuhan had done his reading and annotating digitally?

Some hazards lurk within this question. It can lead, on one hand, to technological determinism and the easy answers it offers (which McLuhan was sometimes all too ready to accept); it can also lead, on the other, to uncritical celebration of digital tools and their affordances (which many in the digital humanities have been all too ready to promote). The biggest hazard, however, is comfortable cynicism about new technologies, leading to the tired lament that no one reads anymore-or the no-true-Scotsman variant, that no one reads properly anymore. The field of book history has largely moved beyond the death-of-the-book anxieties that new digital reading platforms raised over a decade ago, and the most interesting scholarship now investigates the different ways reading happens - not just in the digital present, but also in the pre-digital past, which historians of reading are still exploring. ${ }^{5}$ To be clear, then, I am not posing this question merely to arrive at a predictable, cynical no. Rather, I hope to follow the question through an exploration of how McLuhan read, and what his practices can reveal about the inbuilt assumptions of digital reading platforms.

With this approach I hope to address two apparent oversights in current scholarship on digital reading and annotation. The first is a straightforward question of digital forensics: how can future historians understand the evidence left behind by readers when that evidence is in digital form, not as marginalia and other marks in paper or parchment books, or written ephemera tucked between leaves or pasted inside covers, but as archived digital files? The voluminous scholarship, both theoretical and practical, on digital annotation in recent decades deals almost entirely with the question of how future readers could or should annotate digitally, and how to design new tools accordingly. ${ }^{6}$ This is research in the future conditional tense, undertaken to inform design. What seems to be lacking is research in the past tense: there is a blind spot, or at least a lacuna, in the scholarly literature when it comes to digital annotations as part of the historical record, in the form of ebooks or other files received by an archive. Granted, the historical window for digital annotation is only decades, in contrast to the centuries' worth of marginalia in print and manuscript books studied by H.J. Jackson, Lisa Jardine, Anthony

\footnotetext{
${ }^{4}$ Alan Galey, 'Reading McLuhan Reading Ulysses', in Sarah Sharma (ed.), Many McLuhans or None At All, spec. issue of Canadian Journal of Communication, 44.4 (2019), pp. 503-26.

${ }^{5}$ Even the recent scholarly literature is too broad to summarize here, but some worthwhile recent studies of pre- and post-digital reading include Leah Price, What We Talk About When We Talk About Books: the History and Future of Reading (New York: Basic Books, 2019); Simone Murray, The Digital Literary Sphere: Reading, Writing, and Selling Books in the Internet Era (Baltimore: Johns Hopkins University Press, 2018); and the articles in Deidre Shauna Lynch and Evelyne Ender's two-part special issue of Publications of the Modern Language Association, titled 'Cultures of Reading' (vol. 133, no. 5, 2018, and vol. 134, no. 1, 2019). See also the slightly earlier work cited in note 6 below.

${ }^{6}$ Some parts of this literature build on historical approaches, often citing H.J. Jackson's work (see note 7 below). See Catherine C. Marshall, 'Annotation: From Paper Books to the Digital Library', Proceedings of the ACM Conference on Digital Libraries 1997 (New York: ACM Press, 1997), pp. 131-40; Reading and Writing the Electronic Book (San Rafael, CA: Morgan \& Claypool, 2010), pp. 38-51; Elyse Graham, 'The Past and Futures of Annotation: How Reading Communities Drive Media Change', Book 2.0, 5.1-2 (2015), pp. 59-70; and Melanie Ramdarshan Bold and Kiri L. Wagstaff, 'Marginalia in the Digital Age: Are Digital Reading Devices Meeting the Needs of Today’s Readers?', Library \& Information Science Research, 39 (2017), pp. 16-22.
} 
Grafton, William Sherman, and others who established annotation as an area for literary and historical study. ${ }^{7}$ We may not (yet) have studies of digital equivalents of S.T. Coleridge or Gabriel Harvey, yet it is difficult to imagine that at least some readers worth researching have not integrated digital annotation into their reading practices, given that the technologies have existed for more than twenty years. ${ }^{8}$ There are practical obstacles to this kind of historical research, and indeed to digital archiving itself, not least of which is Digital Rights Management (DRM) protection of ebooks. I explore those questions elsewhere in my current work, but here I wish to imagine McLuhan as a hypothetical digital reader whose received library might include files on floppy discs, iPads with installed reading apps, disc images with system files, and usernames and passwords to online reading services. ${ }^{9}$ Such are the materials of the .txtual condition, as Matthew Kirschenbaum has termed the challenge - and opportunity - facing textual scholars in the age of born-digital records. ${ }^{10}$

The other oversight I will address in the scholarly literature on digital annotation is the tendency to focus on identifiable groups of readers, not individuals, which overlooks the practices of expert readers. This blind spot is understandable given that the social sciences tend to focus on how humans behave in groups, not on individual achievement. Likewise, good user experience design makes use of plausible user profiles, based on empirical study of actual behaviour, for the design of platforms that serve many different kinds of users - not least those with disabilities who have been systematically excluded by reading technologies, new and old. These are valid and necessary approaches to studying digital annotation, and consistent with the disciplinary mores of the social sciences, but in the spirit of humanistic inquiry I would also ask what digital annotation looks like in the hands of an expert reader. McLuhan was just such a reader: his library, annotations, and published scholarship all display evidence of a reading practice that was equal parts deliberate, erudite, systematic, and adventurous - and reading practices which, over time, changed in some ways and persisted in others, evident in Fisher Library books ranging from his student days to the height of his popularity. What, then, can we learn about digital reading and annotation from someone like McLuhan, who did those things exceptionally well in another medium, and whose practices left behind copious evidence in the form of a library available to other researchers?

\footnotetext{
${ }^{7}$ See H.J. Jackson, Marginalia: Readers Writing in Books (New Haven, CT: Yale University Press, 2001) and Romantic Readers: the Evidence of Marginalia (New Haven, CT: Yale University Press, 2005); Lisa Jardine and Anthony Grafton, “'Studied for Action”: How Gabriel Harvey Read His Livy', Past and Present, 129 (1990), pp. 30-78; and William Sherman, Used Books: Marking Readers in Renaissance England (Philadelphia: University of Pennsylvania Press, 2008).

${ }^{8}$ Even in 2002 it was possible to conduct a systematic review of such technologies; see Joanna Wolfe, 'Annotation Technologies: a Software and Research Review', Computers and Composition, 19 (2002), pp. 471-97.

${ }^{9}$ To my knowledge, as of 2020 the only published study of archived writers' uses of annotation technologies is Porter Olsen's analysis of Salman Rushdie's use of the Macintosh Stickies feature (i.e. digital post-it notes) in 'Emulation as Mimicry: Reading the Salman Rushdie Digital Archive', South Asian Review, 40.3 (2019), pp. 17489. On digital writers' archives more broadly, see Matthew G. Kirshenbaum, 'The .txtual Condition: Digital Humanities, Born-Digital Archives, and the Future Literary', Digital Humanities Quarterly, 7.1 (2013): http://digitalhumanities.org//dhq/vol/7/1/000151/000151.html, and Track Changes: a Literary History of Word Processing (Cambridge, MA: Harvard University Press, 2016); and Paul Gooding, Jos Smith, and Justine Mann, 'The Forensic Imagination: Interdisciplinary Approaches to Tracing Creativity in Writers' Born-Digital Archives', Archives and Manuscripts, 47.3 (2019), pp. 374-90.

${ }^{10}$ Kirschenbaum, 'The .txtual Condition'.
} 
McLuhan himself often turned to literature when thinking through questions of media. The works of James Joyce, in particular, functioned for him not merely as a stock of examples, but also as a source of media theory. This was especially true of Finnegans Wake. As Eric McLuhan remarks in his preface to The Laws of Media, 'For many years ... when my father made some large discovery about media or about sensibility he would pop open Finnegans Wake and within a few pages (seldom more than three or four) find that Joyce had been there before him and had gone both farther and faster, and infallibly because navigating by the lines of force in the language'. ${ }^{11}$ McLuhan and others sometimes referred to his approach as 'applied Joyce', recognizing that Joyce's works reframe language, media, technology, and culture in ways that playfully and imaginatively achieve what serious, scientific scholarship cannot. ${ }^{12}$ Throughout his career, McLuhan used Joyce to read media environments, and the availability of McLuhan's own books at the Fisher Library allows us to read Joyce through McLuhan, so to speak. Although the obvious Joyce work to begin with is Finnegans Wake, I leave that daunting task to more competent Joyce and McLuhan scholars, and focus instead on less obvious pathways through $A$ Portrait of the Artist as a Young Man and Ulysses.

Ulysses in particular offers wanderers in McLuhan's library a proleptic experience similar to what Eric McLuhan describes, in that Joyce anticipates our attempts to make sense of McLuhan through his library. Toward the end of Ulysses, when Leopold Bloom has returned late to his home in Eccles Street and said goodbye to Stephen Dedalus, as he prepares to go upstairs to bed he catches sight of his own bookshelves in a mirror. Along with, presumably, his own face, the mirror shows him 'the optical reflection of several inverted volumes improperly arranged and not in the order of their common letters with scintillating titles on the two bookshelves opposite'. ${ }^{13}$ The episode 'Ithaca', in which this passage appears, is structured as a sequence of paired questions (or instructions) and answers, like an interrogation or catechism. The episode's narrator follows this passage with the seemingly straightforward injunction 'Catalogue these books', resulting in a list of twenty-one titles (here are just the first four):

Thom's Dublin Post Office Directory, 1886.

Denis Florence M'Carthy's Poetical Works (copper beachleaf bookmark at p. 5)

Shakespeare's Works (dark crimson morocco, goldtooled)

The Useful Ready Reckoner (brown cloth). ${ }^{14}$

As we have seen in Bloom's own thoughts throughout Ulysses, the profound and the mundane jostle in the same space, with factual reference books sitting next to literature by Shakespeare, the most canonical of English authors, and Denis Florence MacCarthy, an Irish poet and

\footnotetext{
${ }^{11}$ Marshall McLuhan and Eric McLuhan, The Laws of Media: the New Science (University of Toronto Press, 1988), p. $x$.

${ }^{12}$ See Eric McLuhan, 'Joyce and McLuhan', Antigonish Review, 106 (1996), p. 157; and Donald Theall and Joan Theall, 'Marshall McLuhan and James Joyce: Beyond Media', Canadian Journal of Communication, 14.4 (1989), p. 46.

${ }^{13}$ James Joyce, Ulysses, (ed.) Jeri Johnson (Oxford University Press, 1993), pp. 660-62.

${ }^{14}$ Joyce, Ulysses, p. 661.
} 
playwright little remembered today. McLuhan's own well-catalogued library presents similar conjunctions on a larger scale, and the descriptions of Bloom's books read in places like notes in the McLuhan collection's finding aid. Each detail may become a portal to discovery. For example, Richard Wall's 1976 essay 'Bloom's Bookmarks' and the Grinnell Ulysses Collective's delightful digital project 'Leopold Bloom's Bookshelves' both demonstrate what a bookhistorical perspective can discover in a list (and imaginary shelf) like Bloom's. ${ }^{15}$ As James Blackwell Phelan comments in an article on encyclopedism, annotation, and paratexts in Ulysses, Bloom exhibits a 'restless, roving, seeking, intelligence' and a 'complicated enjoyment of information overload': 'Wandering and thinking, Bloom browses and annotates, makes crossreferences, follows leads and fills in gaps, speculating, referencing from memory, wiping his glosses with what he knows ... . He thrives on his world's power to suggest errant possibilities'. ${ }^{16}$ Such was McLuhan's textual and critical practice as well.

More to the point, Bloom's library, like McLuhan's, holds out the promise of confirming the identity we expected to find reflected in it. Bloom is a Jew living in Catholic Dublin: there are works on the Talmud and the life of Christ. Bloom is interested in history and philosophy: the shelves hold works on both. (I leave aside the intriguing question of whether this is Molly's library, too.) Yet Joyce presents Bloom's library in a way that is doubly mediated, first through the reader's imagination - we have to picture the shelf - and second through the mirror's reflection-we have to picture it as Bloom would have seen it, with everything reversed. The mirror also puts a frame around the bookshelves, creating an image not unlike the social cataloguing websites of the present, such as LibraryThing or the now-defunct Shelfari, which allow users to frame their bookshelves as literal and figurative images of themselves. The enframed, mediated library is precisely my concern in this experiment in 'applied Joyce', in which I aim to test the technologies of today's digital reading platforms against the techniques of McLuhan's reading.

\section{Reading McLuhan reading Joyce: a survey of annotation techniques ${ }^{17}$}

What did McLuhan do with his books? Let us begin with one of the most famous passages in Ulysses, the opening of the episode 'Proteus'. Prior to Bloom's introduction into the story, Joyce places the secondary hero Stephen Dedalus (the novel's Telemachus to Bloom's Odysseus) at Sandymount Strand, contemplating the relation between knowledge and sensory experience-the 'ineluctable modality of the visible'. ${ }^{18}$ In Figure 1 we can see McLuhan the annotating reader

\footnotetext{
${ }^{15}$ Richard Wall, 'Bloom's Bookmarks', James Joyce Quarterly, 13.2 (1976), pp. 208-13; Grinnell Ulysses Collective, 'Leopold Bloom's Bookshelves', http://www.math.grinnell.edu/ simpsone/Ulysses/Projects/bookshelf.php.

${ }^{16}$ James Blackwell Phelan, 'Ulysses, Annotation, and the Literature of Information Overload', James Joyce Quarterly, 55.1-2 (Fall 2017-Winter 2018), p. 49.

${ }^{17}$ The discussion of McLuhan's copies of Ulysses in this section appears in a longer version in my article 'Reading McLuhan Reading Ulysses', pp. 507-18.

${ }^{18}$ Joyce, Ulysses, p. 37.
} 
fully engaged with a passage so deeply relevant to his work, and so infamously difficult for many first-time readers. ${ }^{19}$

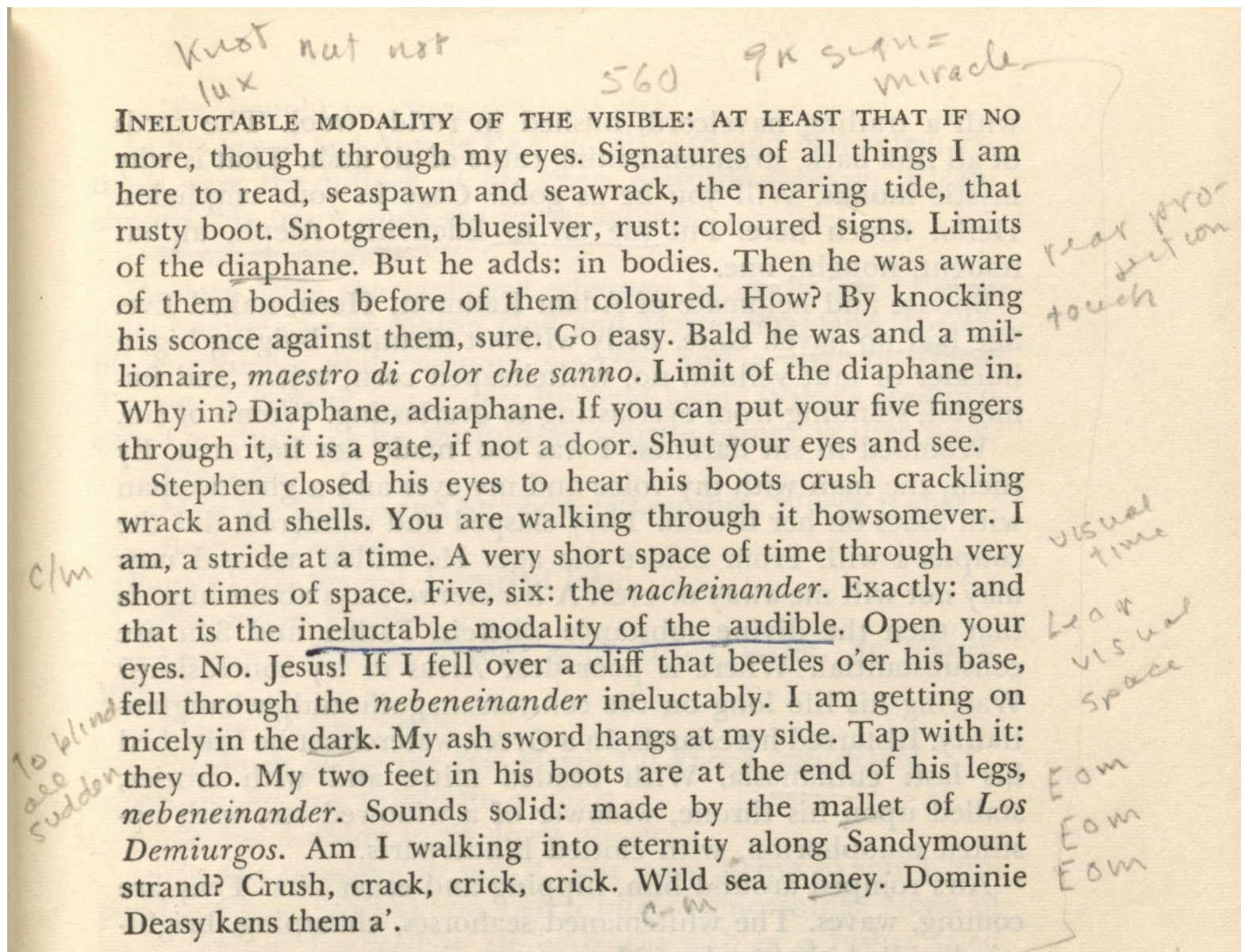

Figure 1. McLuhan's notes on the opening of 'Proteus' in the 1961 Random House edition, p. 37. Manuscript notes reproduced by permission of the Estate of Marshall McLuhan.

To understand annotation as technique — as an application of readerly skill, not just spontaneous scribbling - it helps to organize instances into categories, as follows:

- Underlining. Joyce's sensory variant on his opening phrase, 'ineluctable modality of the audible,' is underlined in pen, and other sense-related words, 'diaphane' and 'dark', are underlined in pencil, along with 'mallet' and 'money'.

- Glossing. McLuhan's most prevalent and interesting notes tend to be glosses, where he draws a linguistic or thematic association out of a word or passage. In the upper-left, he teases the Latin word lux (light) out of 'ineluctable'. Above, he appears to play with the sounds of the near-homonyms 'knot', 'nut', and 'not'—possibly working out the punning possibilities in

\footnotetext{
${ }^{19}$ For his discussion of the passage, see Marshall McLuhan, 'James Joyce: Trivial and Quadrivial', Thought, 28 (1953), p. 90.
} 
the first syllable of 'snotgreen', just below. (In his article 'James Joyce: Trivial and Quadrivial', McLuhan describes Joyce's puns as 'crossroads of meaning in his communication network' ${ }^{20}$ ) Following the margin around clockwise, we see him write media/sensory glosses: 'rear-projection'; 'touch'; 'visual time'; 'visual space'.

- Intertextual cross-references. The breadth of McLuhan's reading is evident in the many references to other texts found in his notes, e.g. 'Lear' written next to Joyce's phrase 'open your eyes', likely a reference to the blinding of Gloucester and blindness as a theme in Shakespeare's King Lear. At many other points in Ulysses, a single name like Aquinas or Swinburne will be pencilled in the margin, whether in recognition of Joyce's highly associative thinking or marking an association of McLuhan's own.

- Intratextual cross-references. Likewise, the depth of McLuhan's reading of Ulysses is evident in the many internal cross-references he creates, much in the spirit of Joyce's intricate self-referential details in the novel (about which more below). Here, the page reference to ' 560 ' in the top margin points to Stephen Dedalus's repetition of the phrase 'ineluctable modality of the visible' hundreds of pages later, in the 'Circe' episode, when he and Bloom visit Bella Cohen's brothel. Next to the repeated line in 'Circe' McLuhan adds a ' 37 ', pointing reciprocally back to its first use in the opening of 'Proteus'.

- Abbreviations referring to McLuhan's own concepts and works. McLuhan had his own shorthand system of self-reference, here visible in the three stacked 'EOM' ('Extensions of Man') notes on the lower right, and the ' $\mathrm{c} / \mathrm{m}$ ' and 'c-m' notes to the left and bottom, which the Fisher library finding aid glosses as 'Center Margin (i.e. fragmented)' and 'Center Without Margin (i.e. inclusive)', respectively (see note 1 on the finding aid, which provides a list of McLuhan's common abbreviations).

Even in this small space of a half-page, we can begin to catalogue a range of McLuhan's annotation techniques, including his use of a systematic vocabulary to connect his reading to his thinking and writing.

Annotations in McLuhan's 1934 edition of A Portrait of the Artist as a Young Man highlight the importance of temporality, especially when interpreting seemingly straightforward instances of cross-referencing. On page 251, McLuhan's interest was apparently caught by a passage where Stephen Dedalus thinks about his resentment toward a young woman, Emma Clery (E.C. in the novel), he encountered in a classroom earlier (Figure 2). McLuhan brackets the passage, draws a vertical line beside it, underlines the phrase 'batlike soul,' and then writes '208', pointing back to an earlier part of the novel. Whether McLuhan committed all these acts of writing at the same time, we cannot know; the medium cannot record whether these marks were made all at the same time, in an unusually emphatic single moment of annotation, or whether these are layers of accumulating marks, each a temporally distinct act of agreement with one's past reading self, as if to say 'yes, this matters.' If the marks were a mix of different hands, or pen and pencil, or pens with different ink, then perhaps we could guess, but reading another reader's marks often means not knowing.

${ }^{20}$ McLuhan, ‘James Joyce: Trivial and Quadrivial', p. 75. 
flung a quick shadow. He had told himself bitterly as he walked through the streets that she was a figure of the womanhood of her country, a batlike soul waking 208 to the consciousness of itself in darkness and secrecy and loneliness, tarrying awhile, loveless and sinless, with her mild lover and leaving him to whisper of innocent transgressions in the latticed ear of a priest. His anger against her found vent in coarse railing at her

Figure 2. McLuhan annotates a passage in his 1934 Jonathan Cape edition of $A$ Portrait of the Artist as a Young Man, p. 251. Manuscript notes reproduced by permission of the Estate of Marshall McLuhan.

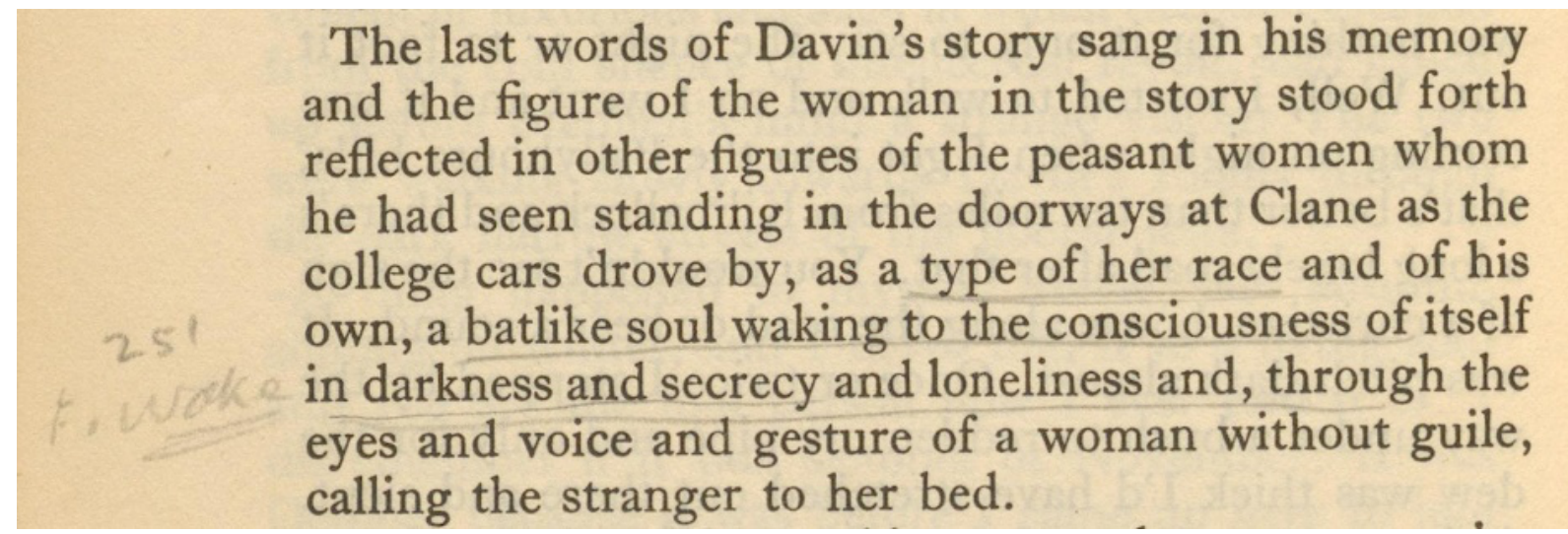

Figure 3. McLuhan annotates a passage in his 1934 Jonathan Cape edition of $A$ Portrait of the Artist as a Young Man, p. 208. Manuscript notes reproduced by permission of the Estate of Marshall McLuhan.

Page 208 (Figure 3) reveals that McLuhan has noticed a Joycean repetition. Here in this earlier passage, Stephen is thinking of a female figure in story he' $\mathrm{d}$ recently heard, and casts her as 'a type of her race and of his own, a batlike soul waking to the consciousness of itself in darkness and secrecy and loneliness'. ${ }^{21}$ McLuhan underlines the phrase (here in italics) that repeats verbatim later in the novel, as well as the phrase 'type of her race', recognizing Stephen's conceptual link between the episodes. In a small but significant extra step, McLuhan also writes ' 251 ' in the margin, creating a double-ended reference. It is worth pausing over this instance to consider the proto-digital qualities of this kind of annotation. When imagining digital annotation, the pitfall of screen essentialism can limit our thinking merely to what is visible, either on the page or the screen. ${ }^{22}$ However, to someone looking at McLuhan's copy of Portrait with the eyes

\footnotetext{
${ }^{21}$ Joyce, Portrait, p. 208, emphasis added. The 'batlike soul' repetition has been noted by critics as well; see John S. Rickard, 'A Portrait of the Animal as a Young Artist: Animality, Instinct, and Cognition in Joyce's Early Prose', Humanities, 6.56 (2017), pp. 13-14; Marian Eide, 'The Woman of the Ballyhoura Hills: James Joyce and the Politics of Creativity', Twentieth Century Literature, 44.4 (1998), pp. 388-89; and Jonathan Allison, 'The Erotics of Heaney's Joyce', Colby Quarterly, 30.1 (1994), p. 26.

${ }^{22}$ On the term screen essentialism, see Nick Montfort, 'Continuous Paper: The Early Materiality and Workings of Electronic Literature', paper delivered at the Modern Language Association Annual Convention, Philadelphia, 28 December 2004, https://nickm.com/writing/essays/continuous_paper_mla.html. See also Matthew G. Kirschenbaum,
} 
of a programmer or text-encoder, McLuhan's notes here do not merely add marks to the pages; they evoke an abstract logical structure that links across the pages of the book. ${ }^{23}$

Such abstract thinking about networks of meaning and reference within books suits Joyce's Ulysses particularly well, given its systematic nature, encyclopedic scope, and sheer size, which distributes intra-textual references across hundreds of pages. Following the theme of annotations that exploit the physical form of the codex book beyond just the blankness of margins, we arrive at McLuhan's prolific use of flyleaves and endpapers. In these blank spaces, McLuhan does some of his most focused and systematic annotation in connection with the books themselves, and many of his books contain lists of references like the one shown in Figure 4. Here, McLuhan uses the endpapers of his 1961 Random House Ulysses to list references pointing back to a relatively narrow range of pages, beginning with page 427 , running down the endpaper to page 493, then turning back to the flyleaf to continue with fairly regular references up to page 554, then jumping forward to page 656 and page 720 . Other references and notes are scattered here and there, but for the most part McLuhan's customized index consists of pairings of page references with brief summaries or reminders.

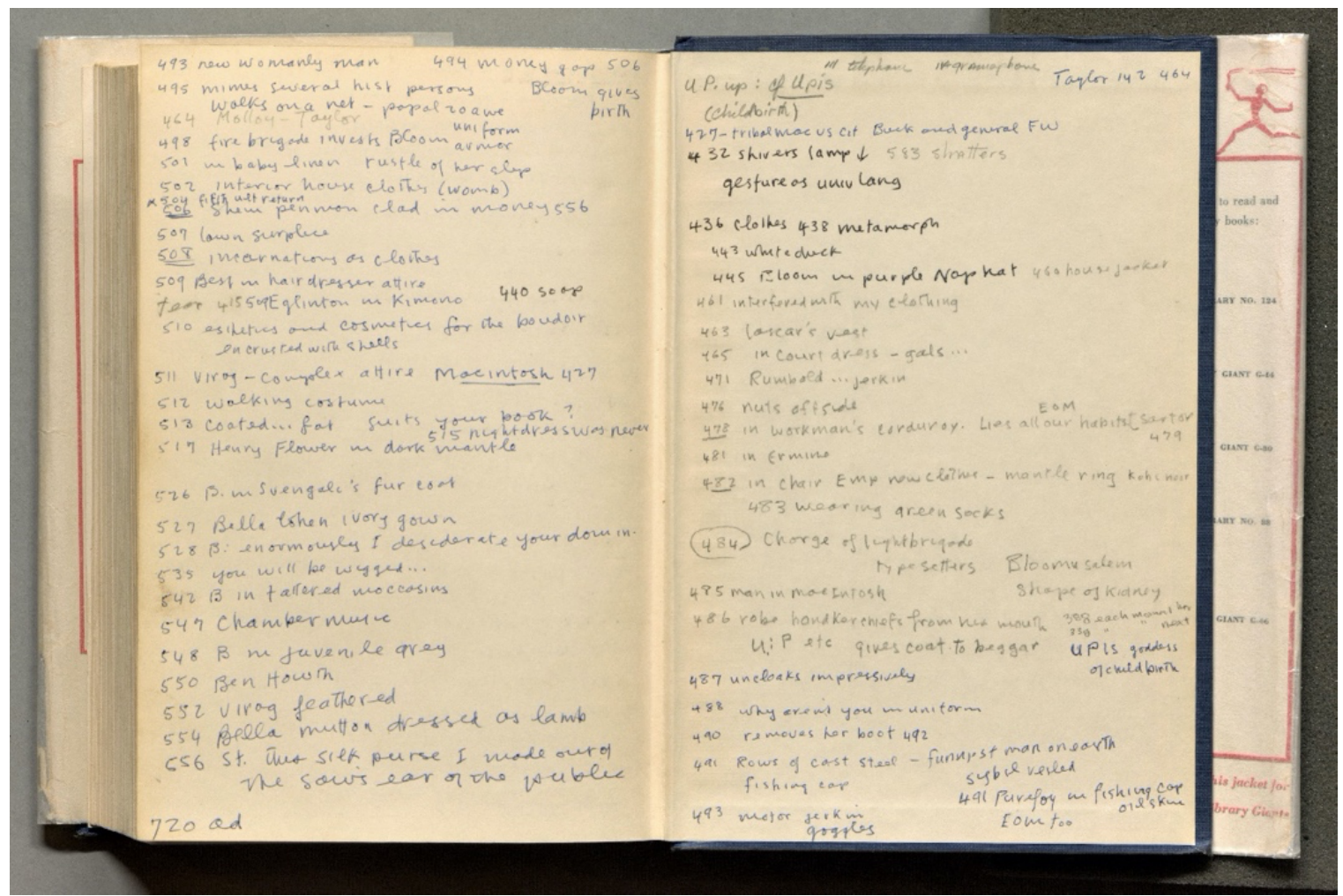

Figure 4. McLuhan's manuscript index on the back flyleaf and endpaper in the 1961 Random House edition. Manuscript notes reproduced by permission of the Estate of Marshall McLuhan.

Mechanisms: New Media and the Forensic Imagination (Cambridge, MA: MIT Press, 2008), pp. 27-43.

${ }^{23}$ Digital markup formalizes this kind of abstract structure through, for example, the Text Encoding Initiative (TEI) Guidelines' < ref> tag and @target attribute; see the TEI P5 Guidelines, part 3.6, https://tei-c.org/release/doc/tei-p5$\mathrm{doc} / \mathrm{en} / \mathrm{html} /$. 


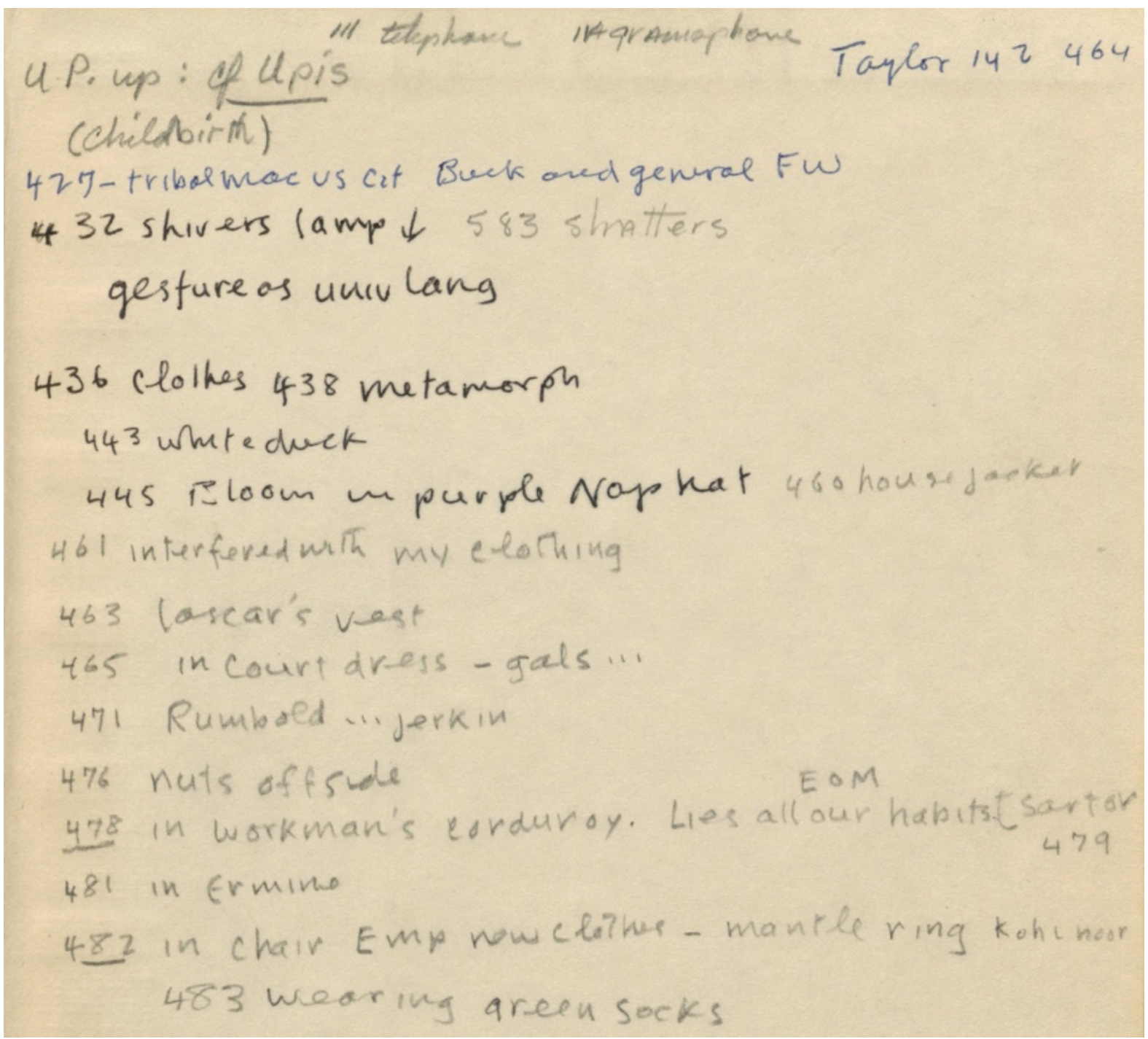

Detail of Figure 4. McLuhan's manuscript index on the back flyleaf and endpaper in the 1961 Random House edition. Manuscript notes reproduced by permission of the Estate of Marshall McLuhan.

As the detail of Figure 4 shows, we can run down a list of things that McLuhan noticed in his reading over a specific span of pages in the 'Circe' episode - things important enough to add to a running list at the back of his book. In this case, his endpaper index seems to be thematically focused on clothing references. More broadly, we can see him using the annotation technique of list-making to bring several connected references together in a single visual field. Researchers do this all the time, and digital technologies such as annotatable PDF files make it even easier to compile lists of internal references in the course of reading, yet it is interesting that McLuhan used the physical book itself to record his list. Flyleaves and endpapers are a book's boundary zones, and yet McLuhan felt the need to include these notes within the physical compass of the book, and not in separate notebooks. He appears to have done this habitually in his reading, and these lists offer glimpses into another part of his workshop as an annotating reader. ${ }^{24}$

${ }^{24}$ These and other annotation habits were likely taught to McLuhan as a student. As Jackson points out, there is a substantial literature on how students should annotate, from Erasmus to Mortimer Adler; see Marginalia (cited in note 7), pp. 48-50. Many of McLuhan's annotation techniques are reflected in that educational literature; e.g. 
McLuhan's 1934 edition of Portrait includes endpaper indexes similar to the ones in his 1961 Ulysses, including an entry for the marginal annotations we have already considered (Figures 2 and 3): '208 batlike soul (F.W.) 231, 251[,] 271'. Here the outward reference to 'F.W.' (Finnegans Wake) raises a particular challenge for those who would trace McLuhan's intertextual references. For example, on page 208, above the 'batlike soul' reference we considered above, Stephen is still thinking of Emma's rejection: 'On all sides distorted reflections of her image started from his memory.' Next to this McLuhan has written the name 'Bella Cohen', the owner of the brothel that Stephen and Bloom visit in Ulysses. Similarly, on the page opposite 251, McLuhan has underlined the sentence beginning 'The soul of the gallant venal city' and written 'The dead' in the margin beside it, likely in reference to the final story in Joyce's Dubliners. The marginal reference to 'F. Wake' visible in Figure 3 completes this set of open-ended references; taken together, their ambiguity contrasts with the highly specific intratextual references of the 'batlike soul' repetition.

With these significant but vague pointers, the reader of McLuhan's annotated Portrait is presented with intriguing but incomplete evidence. Presumably McLuhan the re-reader, coming upon his own notes pointing to Bella Cohen, 'The Dead', and Finnegans Wake would have known what to do with them; this is the kind of note one writes to remind oneself of what one already knows. The general thematic connections are no mystery in these cases (except perhaps with Wake, which is relevant to nearly anything), but what specifically did McLuhan have in mind when he took the trouble to make these notes? Considered in this light, the pencilled marks 'F. Wake' in Figure 3 cannot serve as a proto-hypertext link pointing back to Finnegans Wake directly. Rather, they indicate a pathway routed via McLuhan's own experience, memory, and interpretive capacity. Presumably McLuhan, like other readers, encountered his own notes from time to time as though written by a stranger.

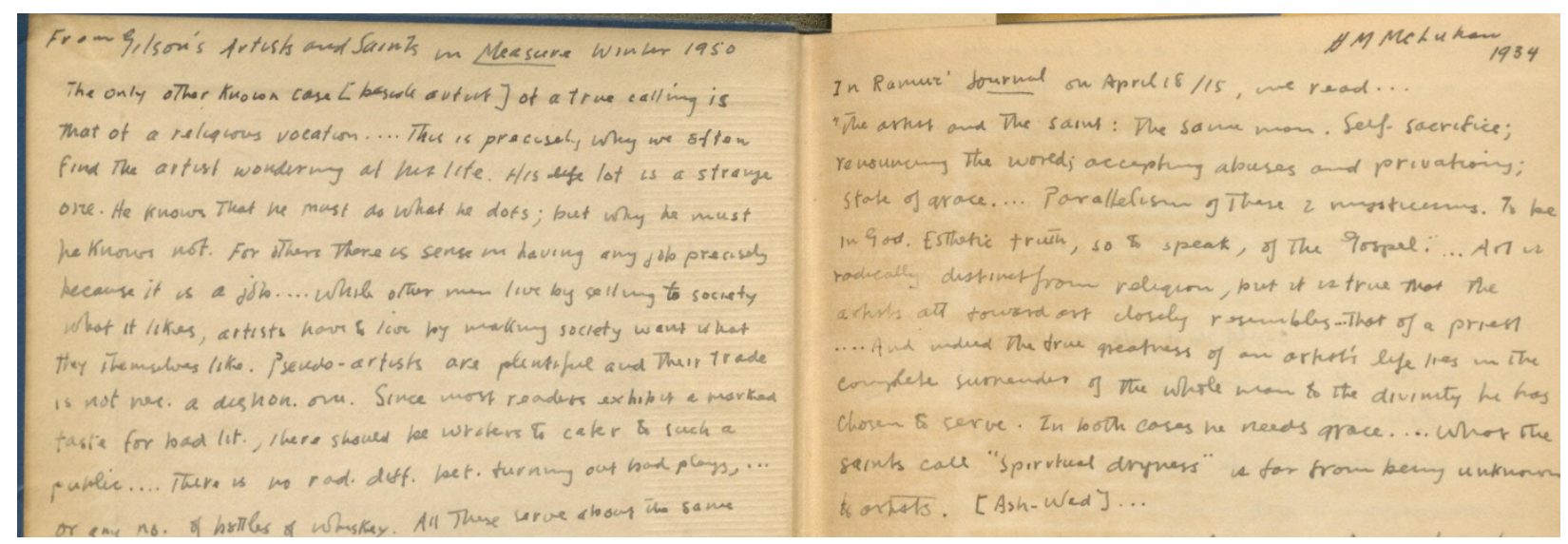

Figure 5. Owner's inscription and critical extract copied into the opening flyleaves of McLuhan's 1934 edition of $A$ Portrait of the Artist as a Young Man. Manuscript notes reproduced by permission of the Estate of Marshall McLuhan.

compare his notes on the 'Proteus' opening with Adler's advice in How to Read a Book, first published in 1940 (rev. ed. with Charles Van Doren; New York: Simon \& Schuster, 1972), pp. 49-52. 
For the purposes of digital modelling, two important qualities have emerged in these examples, the first being the importance of abstract intellectual structures created (or recognized) through annotations, and the second being the mix of vagueness and specificity in certain types of references. A third relevant feature is the complex temporality of annotation, where marks on pages may result from repeated, layered acts of reading, only some of which may be discernable. This phenomenon becomes especially visible in the front flyleaves of McLuhan's 1934 edition of Portrait, where he has employed yet another annotation technique visible in his other books: the copying of critical extracts. On the recto flyleaf (Figure 5), the inscription 'H.M. McLuhan 1934 ' indicates that McLuhan probably acquired this book in the year it was published, while he was a student at Cambridge encountering Joyce's works though his studies with F.R. Leavis and others. As he did with his student edition of Ulysses, he has copied at length a critical extract using the book's blank leaves. ${ }^{25}$ Unlike his copied extracts in his student Ulysses, however, McLuhan here includes a nearly complete bibliographical reference to the extract's source: Etienne Gilson's essay 'Artists and Saints,' from the journal Measure, and, notably, from an issue published in 1950 (visible on the verso flyleaf in Figure 5). Evidently, sixteen years after McLuhan acquired this book he returned to this copy and felt the Gilson extract was important enough to incorporate into the body of the book. ${ }^{26}$ In this example, the two dates facing each other across the same opening make clear the temporal layering of reader's marks, but similarly layered temporalities - representing acts of reading that may have happened decades apart — may be present in any group of annotations, even if they seem straightforwardly readable. As much as McLuhan's annotation techniques call our attention to the many uses of the space of the printed page - and especially the white spaces - it is also essential to remember the layered temporalities of the annotated page, especially when the marks themselves carry no timestamp.

\section{Imagining McLuhan’s digital marginalia}

Having reviewed some of McLuhan's annotation techniques in his copies of Ulysses and Portrait, I will turn to a small experiment I undertook in attempting to replicate some of McLuhan's annotations using digital platforms. I use the term experiment here informally, similar to Adrian Johns's approach in his 2009 experiment in using a Sony Touch reader over several months as a substitute for printing any work-related documents. ${ }^{27}$ Like Johns, my goal is not scientific generalizability but simply the knowledge that can only come from first-hand experience, when the unexpected can come into view.

\footnotetext{
${ }^{25}$ McLuhan's student edition of Ulysses was the two-volume Odyssey Press edition from 1933; for more on his annotations in these copies, see my companion article, 'Reading McLuhan Reading Ulysses' (cited in note 4).

${ }^{26}$ Around the same time, McLuhan also referenced Gilson's book The Unity of Philosophical Experience in his article, 'Joyce, Aquinas, and the Poetic Process', Renascence, 4.1 (1951), p. 8.

${ }^{27}$ Adrian Johns, 'As Our Readers Go Digital', keynote address for When the Books Leave the Building: the Future of Research Libraries, Collections and Services, RLG Partnership Symposium, Newberry Library, Chicago, 11 June 2010 [audio recording, written version, and slides at http://www.oclc.org/research/events/2010-06-11.htm].
} 
I began with two practical, applied versions of the overarching question I asked in the introduction:

1. If McLuhan had done his reading with today's digital technologies, what might his practice have looked like, given how systematic, deliberate, and skilled he was as a reader and annotator, and given the capabilities of digital annotation tools widely available in $2021 ?$

2. If McLuhan had somehow left an annotated digital library behind, and it was archived in a way that provided direct access to the files, what could researchers learn from these digital files as sources of historical evidence for reading?

To be clear, I am not imagining a thorough counterfactual that posits how McLuhan would regard today's technologies. In 2011, Slate commentator John Dickerson famously quipped that attempting to annotate ebooks on an iPad is 'like eating candy through a wrapper', but I am not attempting to recruit McLuhan for any side in the debate over the viability of reading on screens. ${ }^{28}$ For that matter, I am not claiming that McLuhan would have been a digital reader at all; the most I would suggest is that he would have made his choices conscientiously. The object of this experiment is not McLuhan himself. Indeed, if there is one thing that McLuhan's library can teach us, it is that as soon as we begin to think we've joined in someone else's prior act of reading, we're thrown back into contemplating our own. Just when one desires the annotated book to be a window, it can turn into a mirror.

In that spirit, and with these caveats, I began by attempting to replicate some of McLuhan's marginalia on digital versions of Ulysses in two common ebook formats, PDF and EPUB, using two widely available iPad aps, iAnnotate (for the PDF) and Apple Books (for the EPUB). ${ }^{29}$ The choice of editions was the next step, and with Ulysses it is a consequential choice given the text's famously controversial editorial history. I was not able to locate a digital version of any of the editions in the McLuhan library, but through Apple Books I was able to purchase an EPUB version of something comparable, the 2000 reprint of the 1992 Penguin edition, with an introduction and notes by Declan Kiberd. (The most recent edition of Ulysses in McLuhan's library is the 1968 Penguin.) For the PDF version, I traded scholarship for convenience by downloading a PDF file from Project Gutenberg. ${ }^{30}$ I would like to think McLuhan would have been more careful about his choice of edition, but that question is beyond the scope of my informal experiment. For my purposes, what matters is file formats, interfaces, and their affordances in relation to McLuhan's annotating practices.

\footnotetext{
${ }^{28}$ John Dickerson in John Swansburg, 'I Hate My iPad', Slate (February 17, 2011), https://slate.com/news-andpolitics/2011/02/i-hate-my-ipad-can-my-tablet-loving-slate-colleagues-convince-me-i-didn-t-just-waste-600.html.

29 To create the annotations I used iAnnotate version 4.6.5, Apple Books version 2.4, and a late 2013/early 2014 iPad running iOS 12.4.7. I examined the files on a MacBook Pro running macOS Catalina version 10.15.4.

${ }^{30}$ One textual error typical of Project Gutenberg texts, visible in Figure 6, is the mis-formatting of the final line as prose ('Won't you come to Sandymount, Madeline the mare?'). In authoritative editions that follow the 1922 text, this is inset and italicized as two lines of verse, emphasizing that Stephen is composing throwaway poetry to accompany the sounds and rhythms of the beach.
} 
On his wise shoulders through the checkerwork of leaves the sun flung spangles, dancing coins.

lux knot nut not $\quad 560 \quad$ sign $=$ miracle

Ineluctable modality of the visible: at least that if no more, thought through my eyes. Signatures of all things I am here to read, seaspawn and seawrack, the nearing tide, that rusty boot. Snotgreen, bluesilver, rust: coloured signs. Limits of the diaphane. But he adds: in bodies. Then he was aware of them bodies before of them coloured. How? By knocking his sconce against them, sure. Go easy. rear
projection touch

Bald he was and a millionaire, maestro di color che sanno. Limit of the diaphane in. Why in? Diaphane, adiaphane. If you can put your five fingers through it it is a gate, if not a door. Shut your eyes and see.

Stephen closed his eyes to hear his boots crush crackling wrack and shells. You are walking $\mathrm{c} / \mathrm{m}$ through it howsomever. I am, a stride at a time. A very short space of time through very short times of space. Five, six: the nacheinander. Exactly: and that is the ineluctable modality of the audible. Open to blind your eyes. No. Jesus! If I fell over a cliff that beetles o'er his base, fell through the nebeneinander all ineluctably! I am getting on nicely in the dark. My ash sword hangs at my side. Tap with it: they do. My two feet in his boots are at the ends of his legs, nebeneinander. Sounds solid: made by the mallet of Los Demiurgos. Am I walking into eternity along Sandymount strand? Crush, crack, crick, crick. Wild sea money. Dominie Deasy kens them a'. Won't you come to Sandymount, Madeline the mare?
visual time Lear visual space

Figure 6. A reconstruction of McLuhan's annotations on the opening of 'Proteus', as seen in Figure 1, using a PDF file read with the app iAnnotate on an iPad.

Figure 6 shows my attempt to replicate McLuhan's notes on the opening of the 'Proteus' episode, previously seen in Figure 1, by annotating a PDF file in iAnnotate. There is a risk that this kind of comparison can draw a false sense of equivalency between media based on appearance alone, so my focus here is on process and function more than product and form. The iAnnotate app allows a reader to underline, and to add words which may be positioned anywhere on the page, such that proximity can indicate association. As with marginalia in pencil and ink, colour can vary according to the reader's own system, or simply to indicate different passes through the text, as we can see in Figure 1. (In Figure 6, I have made all of my annotations red for the sake of clarity.) My positioning of the digital marginalia is imprecise, and reflects guesswork in several cases, but what matters here is the functionality it reveals.

As we saw in the previous section, McLuhan used a range of annotation techniques even in this one small sample, from glosses (e.g. 'lux'), to intratextual references (e.g. '560'), to intertextual references (e.g. 'Lear'), to shorthand abbreviations (e.g. 'Eom'). With iAnnotate I was able to replicate the appearance of these marks in most respects, and with relative ease. ${ }^{31}$ However, as one iAnnotate's original creators, Stephen Hockema, rightly pointed out in an email conversation with me about this research, there is more to an annotation than its appearance: to understand annotation as an affordance, one must also consider the contexts and intentions that

\footnotetext{
${ }^{31}$ iAnnotate's freehand pencil feature also makes it possible to reproduce the line McLuhan draws from his 'sign = miracle' note at the top down the side of the paragraph, though I have omitted it in this image for clarity. I suspect that McLuhan might also have used iAnnotate's stamp feature for repeated abbreviations such as 'Eom'.
} 
may define any given act of annotation. The challenges of recovering those contexts and intentions from material evidence is one of this article's central themes, and one methodological strategy is to take a comparative approach to annotation platforms.

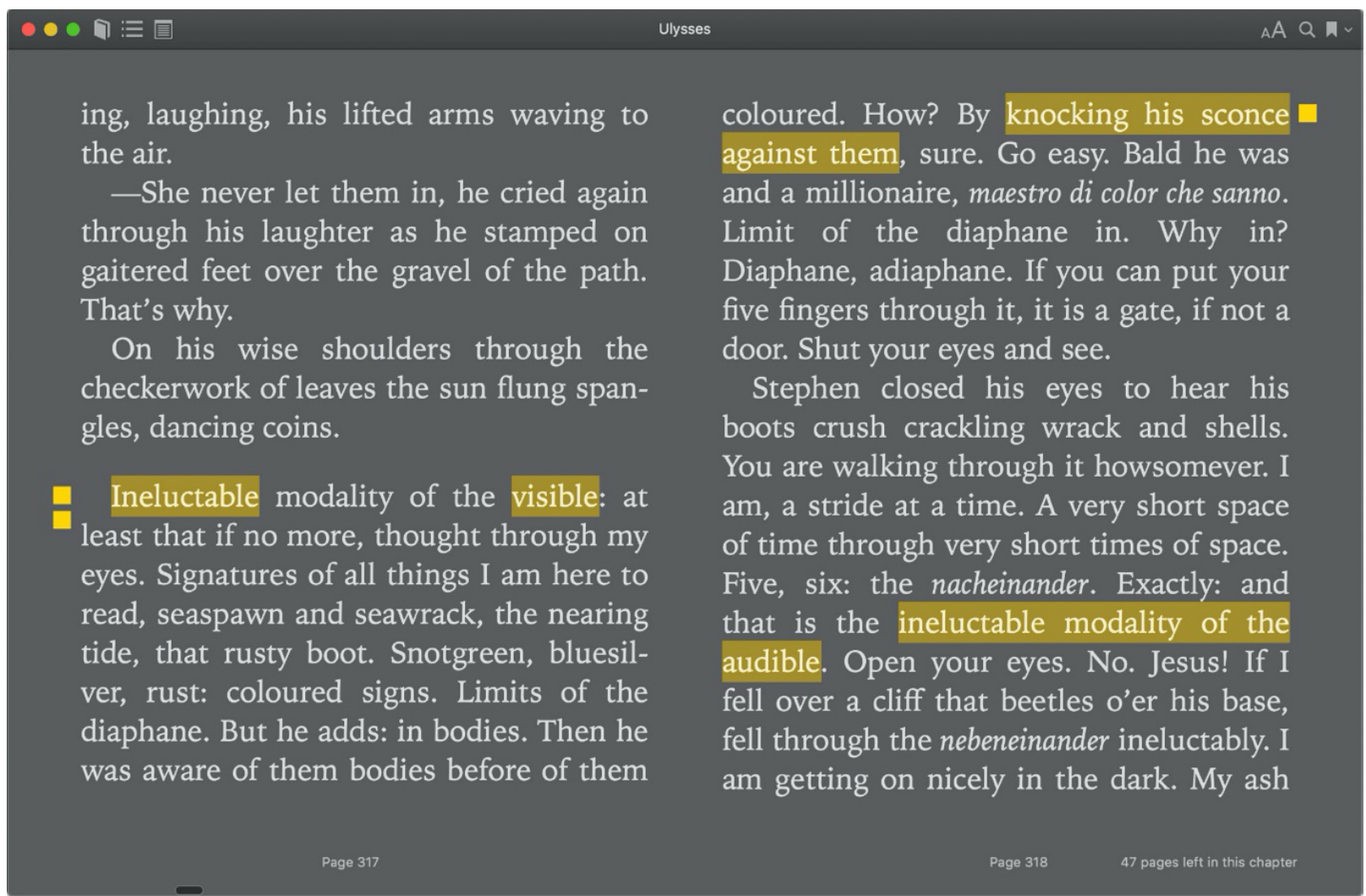

Figure 7. An incomplete reconstruction of McLuhan's annotations on the opening of 'Proteus', as seen in Figure 1, using an EPUB version of Ulysses read with the Apple Books app on an iPad.

Annotating Ulysses as a PDF in iAnnotate revealed a great range of affordances, but annotating Ulysses as an EPUB ebook in Apple Books was another matter. As Figure 7 shows, it was not possible to mark up the page such that all marginalia remain visible at a glance. It is possible to open a list of one's notes on the side of the app window, which aids readability but at the expense of normalizing their appearance and placement. The app also requires each annotation to be anchored to specific words or phrases in the main text; one cannot simply write a broadly associative annotation (e.g. 'Lear') in the margin to flag a thematic link (as McLuhan was likely doing for Shakespeare's King Lear and the theme of blindness). Apple Books thus enforces an explicit link between text and note. Finally, while underlining is possible (as in the case of 'ineluctable modality of the visible') similar non-linguistic marks like vertical lines in the margin (e.g. see Figures 1 and 2) are not possible. Apple Books does incorporate search resources into its reading interface, such that one can select and look up single words (e.g. 'nacheinander') in an integrated dictionary, and look up whole phrases (e.g. 'maestro di color che sanno', from Dante's Inferno) on Wikipedia or the open Web. However, McLuhan's library suggests that he carefully assembled secondary and reference sources to support his reading. Would he have settled for the default dictionary or other resources that Apple's designers 
decided to build in? My guess is that he would have bypassed those and used his own more specialized resources, especially for philological questions. In any case, it is difficult to imagine McLuhan or any other serious annotating reader getting very far with Apple Books.

The PDF standard itself functions as a theory of reading, which is applied in different ways in different applications, but also points us toward the portability of annotation practices and the interoperability of tools across platforms. ${ }^{32}$ In a similar way, McLuhan's endpaper indexes represent the most proto-digital of his annotation practices, and in this regard he would have been partially supported by digital annotation platforms. Even without making the leap to more specialized software such as Zotero or Evernote, a systematically annotating reader like McLuhan could produce a synoptic view of annotations on a PDF file using iAnnotate's typewriter feature, or by opening the same annotated PDF in the macOS app Preview and opening the 'Highlights \& Notes' sidebar. ${ }^{33}$ Even Apple Books includes a synoptic view of reader annotations.

However, McLuhan's endpaper indexes nonetheless exceed these features in complexity, in that his indexes usually connect a single topic to multiple points in the text. As we have seen, they can afford the researcher a sense of McLuhan's overall interests in a given stretch of pages. None of the synoptic note views mentioned here would permit that kind of insight, though it is plausible to imagine McLuhan making use of more powerful indexing platforms - in combination with his own memory and his eye (and ear) for serendipitous connections. Overall, one conclusion we can safely draw from this experiment is that available digital technologies for digital annotation would likely operate in tension with known techniques for annotation, as embodied in a skilled reader such as McLuhan. That both of these italicized words derive from the same root (techne) serves as a reminder of McLuhan's own arguments about the indivisibility of humans and their tools. The lesson to be drawn, I believe, is about the importance of technique, not just tools - that is, the techne we internalize and cultivate within ourselves, not just the techne we pay for in the app store. As readers in the digital age we need both.

My second question above - what could researchers learn from McLuhan's library if it had come to us in digital form?-yields more promising results than the first. In considering this question, I leave aside the vexed issue of the supposed ephemerality of digital records, and focus on the forensic question of what McLuhan's library could tell us if it reached us as digital files (or, ideally, as a complete digital archive, including the software he used and disc images of his computer system). As Kirschenbaum's work has shown in particular, one of the paradoxes of the .txtual condition is that digital files are often said to be ephemeral, yet at the same time digital environments can capture and preserve remarkably precise records of the acts of reading and writing. With some forms of digital annotation, digital platforms can offer evidence of reading practice on a level of detail that those of us working with hand-press era or manuscript books can only dream about.

\footnotetext{
${ }^{32}$ For a list of annotation types supported by the PDF format, see Adobe Portable Document Format Reference, 6th ed., ver. 1.7 (Adobe Systems Incorported, November 2006), https://www.adobe.com/devnet/pdf/pdf_reference_archive.html. Table 8.20 on pp. 615-16 provides a (relatively) concise summary of the types of annotation the PDF standard supports.

${ }^{33}$ However, Preview's 'Highlights \& Notes' sidebar (in its current version, 11.0) unhelpfully omits notes written directly onto a PDF file, called 'FreeText' notes in the language of the PDF standard (cited above, p. 623); it shows only the contents of sticky note annotations and underlined passages.
} 
Timestamps are the most consequential form of evidence one could glean from digital annotations. The temporality of handwritten marginalia can be elusive, leaving researchers with more questions than answers. As we saw in the examples from McLuhan's copy of Portrait in the previous section, years and decades may pass between specific acts of annotation. The marginalia in that book helpfully includes some years to give us a rough framework, but what of an annotated page like the opening of 'Proteus' in Figure 1? In that image we may be seeing many McLuhans in conversation with each other, separated by days, years, or decades but sharing the same pages as their common ground. The presence of marginalia in both pencil and pen hints at McLuhan's multiple passes over this page with writing instrument in hand, but the physical book cannot tell us how many or when. Some digital files, however, can answer these questions down to the second, depending on the annotation platform and the way it works.

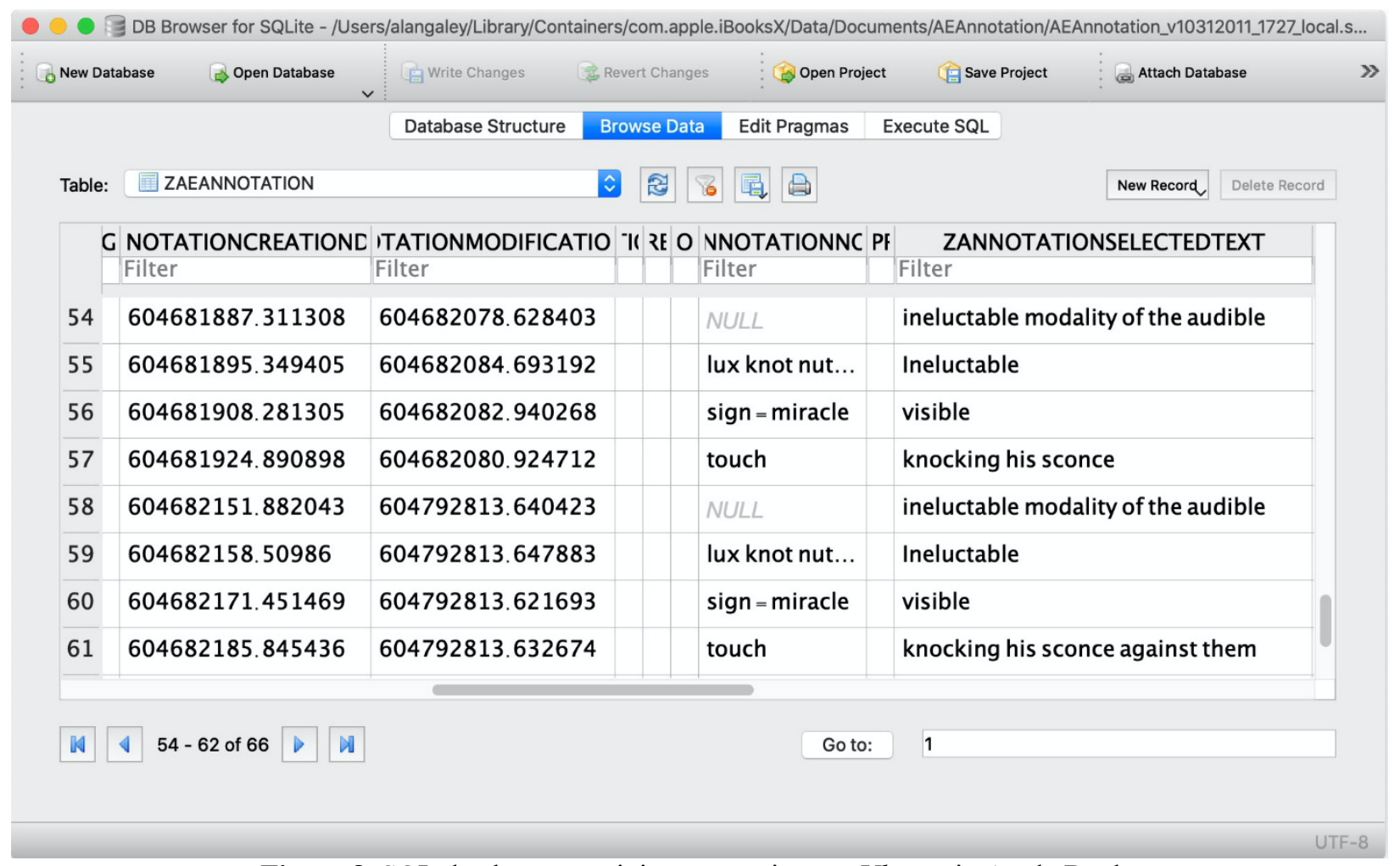

Figure 8. SQL database containing annotations to Ulysses in Apple Books (viewed with DB Browser for SQLite v3.11).

Apple Books, for all its limitations, would be a forensic researcher's dream come true if a digital annotator's entire computer system, including operating system files, could be archived. In the current version of macOS Catalina, reader annotations on specific ebooks are stored in an SQLite database file buried deep — but nonetheless accessible—in the operating system files. ${ }^{34}$

\footnotetext{
${ }^{34}$ In the current version of macOS Catalina (10.15.4), the location path of the annotation database file is Macintosh $\mathrm{HD} /$ Users/[username]/Library/containers/com.apple.iBooksX/Data/

Documents/AEAnnotation/ AEAnnotation_v10312011_1727_local.sqlite. Users may need to change system settings to make hidden folders and files visible.
} 
The file itself is not DRM encrypted, and may be opened using any application that can read .sqlite files. ${ }^{35}$ Figure 8 shows the database's 'ZAEANNOTATION' table, which contains my own annotations on the Ulysses ebook shown in Figure 7. Each row in Figure 8 contains metadata for a single annotation, and the visible columns, from left to right, display:

1) the timestamp for the note's creation;

2) a second timestamp for the note's most recent modification;

3 ) the text of the annotation (e.g. 'lux knot nut not');

4) the annotated text in the source (e.g. 'Ineluctable').

There are many other metadata fields for each note, but to simplify Figure 8 I have collapsed some columns and expanded others to highlight the relevant ones.

The most important data here are the timestamps. For example, the date modified timestamp in column 2 for the first annotation in Figure 8 ('touch'), when converted to humanreadable format gives a date of Saturday, February 29, 2020 10:14 AM, which happens to be when I last modified this note. ${ }^{36}$ This source of temporal data does not provide an infallible record of reader annotations: timestamps are normally standardized to Greenwich Mean Time, meaning that a researcher would need to know the time zone where the annotation was made, and would need to account for potential inaccuracies in the local computer's internal clock. ${ }^{37}$ However, if one allows for these variables - and if only Apple Books became a robust platform for annotation, worth using by skilled annotators - then a seemingly mundane file such as 'AEAnnotation_v10312011_1727_local.sqlite' might become a treasure trove for marginalia researchers. They would not even need to construct a database to analyze patterns in the notes; the file already is a database, and supports searches and structured queries with the right software.

As noted above, PDF files hold the greater potential for rich annotation practices, and the same is true for forensic research, too. The PDF standard includes a remarkably detailed annotation model — one far more nuanced than that of Apple Books - which allows annotations to be encoded in the PDF file itself, without the need for a separate file like the SQLite database we just examined. Figure 6 shows my annotated Ulysses PDF in standard PDF reading software (Preview), but if we instead open the file with a Hex editor or a standard text editor to show the underlying bitstream's encoding, we may be able to recover metadata for each annotation. Annotations on a PDF file are encoded within the file itself as discrete objects with defined sets of parameters and values, and this information may remain human-readable amid the seemingly random jumble of characters that represents the bitstream. For example, one of the McLuhan annotations I added on the PDF corresponds to the following human-readable object:

\footnotetext{
${ }^{35}$ For this experiment, I used a free and open-source application called DB Browser for SQLite (version 3.11): https://sqlitebrowser.org/.

${ }^{36}$ These timestamps use what is known as the epoch time format, in which a single integer indicates the total number of seconds that have passed since a given benchmark date. The Unix operating system uses midnight GMT on January 1, 1970, whereas macOS Catalina uses January 1, 2000. For a simple web-based conversion tool, see https://www.epochconverter.com/coredata.

${ }^{37}$ See Noah Sussman, 'Falsehoods programmers believe about time', Infinite Undo! (17 June 2012), http://www.FalsehoodsAboutTime.com.
} 


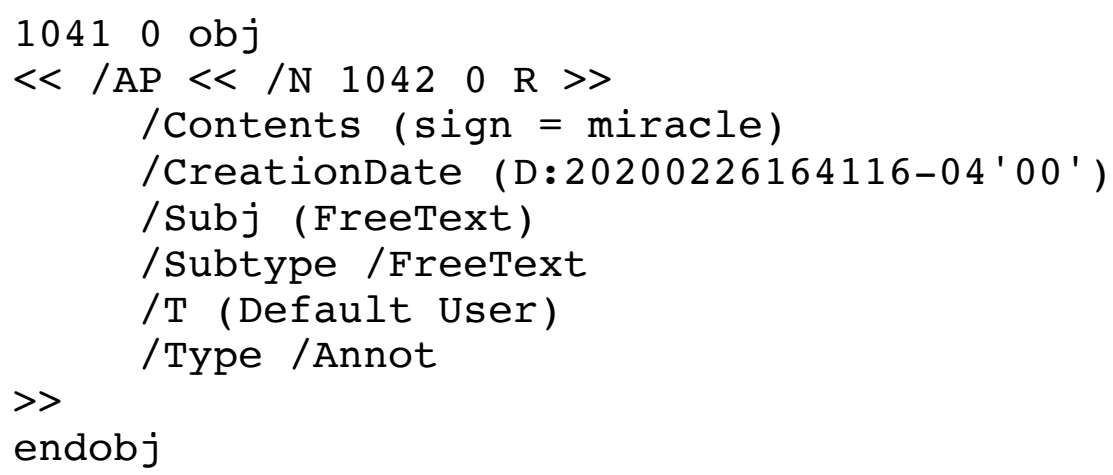

(To simplify this example, I have added line breaks and indentation, and omitted lines of metadata that are not directly relevant.) As with the Apple Books example above, the critical pairing is the content of the note (e.g. 'sign = miracle') with the value of the 'CreationDate' key. ${ }^{38}$ As dry as this metadata may seem, when taken together it reveals a detailed picture of my own annotation of Ulysses on a February afternoon in 2020. If a prolific annotating reader like McLuhan left behind books and articles as PDF files, the standardized structure of the encoded notes could make it feasible to search algorithmically for patterns across the entire library.

As a final observation on the forensics of digital annotations, one of the most intriguing possibilities for future research is the strange persistence of deleted annotations. With PDF files in iAnnotate and EPUB files in Apple Books, notes that have been created but later deleted by readers may still be recoverable. For example, Figure 8 shows repeated notes (and a spurious note in the bottom row) that I had deleted, and were no longer visible in the reading interface, but nonetheless remain in the SQLite database file. Similarly, notes created and then deleted from a PDF file in iAnnotate may remain as human-readable objects encoded in the file itself, even after their apparent deletion in PDF reading software. ${ }^{39}$ Book historians are already familiar with the capacity of paper and parchment to remember its erasures, which in some cases permit the recovery of palimpsests. However, the persistence of deletions in the bitstreams of digital files opens up even greater possibilities for future historians of digital reading - if only readers would leave those traces, as McLuhan did in his own books.

\section{Conclusion: the ineluctable modality of the recoverable}

To return to my opening question, the forensic possibilities of digital annotations hold out the promise of a queryable and knowable library, though as far as I am aware, a McLuhan-level digital annotator remains to be discovered among the born-digital archives held by institutions. If such a trove of digital marginalia is ever discovered, I anticipate it will be found in connection with PDF documents, not ebooks in EPUB and related formats. As Johanna Drucker has argued, the limitations of ebooks today result partly from their designers' limited understanding of printed books: 'There has been too much emphasis on formal replication of layout, graphic, and

\footnotetext{
${ }^{38}$ Dates in PDF objects are formatted as a single string of numbers that combines, in order, the four-digit year, followed by the two-digit month, day, hour, minute, and second, plus characters to indicate time zone. In this example, the 'CreationDate' value translates to February 26, 2020, 4:41:16 pm, EST, when I created the note. See pp. 160-61 of the PDF standard, cited in note 32.

39 The reasons for this phenomenon are explained in the PDF standard, p. 95, cited in note 32.
} 
physical features and too little analysis of how those features affect the book's function. Rather than ... simulating the way a book looks, then, designers might do well to consider extending the ways a book works' ${ }^{40}$ McLuhan's own writing about print culture tends to reproduce this error, for instance by treating over 500 years of printed books as though they were all the same kinds of objects, with the steamroller adjective Gutenberg flattening the historical differences where book historians today explore new questions of mind and media. Print was never just one thing, and print cultures tend to be more plural and protean than we realize. Yet the evidence of McLuhan's own library hints at an understanding closer to Drucker's, and his marginalia indicates that 'the ways a book works', in his hands, were subtle and wide-ranging indeed. How McLuhan worked his books remains a question worth exploring in his library, which, as Peters rightly suggests, stands as McLuhan's Gesamtkunstwerk, waiting to be read at the Fisher Library in Toronto. It is also a question that could help future ebook design find inspiration in a marginalia-rich past that we are still discovering.

However, even if my answer to the opening question about Peters's claim is a cautious $y e s$, and I hold out hope for future digital marginalia research, it is also worth closing with another of Peters's provocations: 'Media are perhaps most interesting when they reveal what defies materialization'. ${ }^{41}$ Even if one could know the precise moment, down to the second, of every discrete act of annotation in McLuhan's library, by Marshall, Eric, and other hands present in the books, would it be worth knowing? It would answer many factual questions about who wrote what and when, but there is no escaping the interpretive burden of the questions why and how. Why was McLuhan's interest in Joyce so sustained, and how did he operationalize his rereading in his library and his scholarly workshop more broadly? This article and the others in this special issue of Textual Practice begin to answer these questions for Joyce and other writers, but it is only a beginning for a project that is Borgesian in scope and fascination alike. The lesson for researchers of material textuality may be that any PDF timestamp like '20200226164116-04' is only a few short steps away from the kind of labyrinthine structures of cognition and reading that fascinated McLuhan, Joyce, and Borges alike. ${ }^{42}$

Reading Joyce often means confronting encyclopedism's temptations and failures alikeeven more so when reading McLuhan reading Joyce. Seamus Heaney once said of Joyce that 'he is like an immense factory ship that hoovers up all the experience from the bed of the Irish psyche. If you open Ulysses or A Portrait, or Dubliners, you are reading yourself'. ${ }^{43}$ Jacques Derrida echoed the fishing metaphor, claiming that 'We are all caught in this net': 'Everything we can say about Ulysses ... has already been anticipated [by Ulysses itself], including ... academic competence and the ingenuity of metadiscourse'. ${ }^{44}$ Yet the idea of a library, or even a

\footnotetext{
40 Johanna Drucker, SpecLab: Digital Aesthetics and Projects in Speculative Computing (University of Chicago Press, 2009), p. 166, emphasis in original.

${ }^{41}$ Peters, Marvelous Clouds: Toward a Philosophy of Elemental Media (University of Chicago Press, 2015$)$, p. 11.

42 On labyrinths, see McLuhan, 'Joyce, Aquinas, and the Poetic Process.'

${ }^{43}$ Seamus Heaney, Irish Times (13 September 1984), qtd. in Allison, 'The Erotics of Heaney’s Joyce', p. 25.

${ }^{44}$ Jacques Derrida, 'Ulysses Gramophone: Hear Say Yes in Joyce', in Derek Attridge (ed.), Acts of Literature (New York: Routledge, 1992), p. 281. Not coincidentally, Derrida couches his point about encyclopedism here within an elaborate computer metaphor, and later posits what amounts to a digital humanities project in algorithmic criticism, focused on the word yes in Ulysses (pp. 305-6). He even includes a lengthy footnote of instances, ending on the encyclopedic note that 'a systematic typology would be interesting' (p. 306, fn. 25).
} 
single book, that contains the totality of experience or discourse returns us to Leopold Bloom on his way to bed in Eccles Street, noticing his own books in the mirror. Framed along with his books in the reflection-not unlike COVID-19-era-academics' self-framings in front of bookshelves for videoconferencing - the picture invites the question of whether Bloom is explained by his books, any more than McLuhan is explained by his. It is a question for McLuhanites, book historians, digital media scholars, and archivists all alike. The descriptive mode of this passage in Ulysses even evokes the related disciplines of enumerative and descriptive bibliography (which existed when Joyce was writing), just as the larger catechistic form of the 'Ithaca' episode evokes encyclopedism through its question-and-answer structure. The episode in which we encounter Bloom's books becomes, itself, a great positivistic heap of facts, and all seems potentially knowable if only someone asks the right questions. (As Jeri Johnson notes, 'Ithaca' asks eight times as many what questions as why questions. ${ }^{45}$ ) Like Bloom pausing on the stairs, catching his own bibliographical reflection momentarily, the question of total knowledge hangs suspended in the gap between the recoverable and the desire to know.

${ }^{45}$ Jeri Johnson (ed.), Ulysses, by James Joyce (University of Oxford Press, 1993), pp. 958-59. 